\title{
Performance Evaluation of a Screw Type Oil Expeller for Extraction of Sesame Oil
}

\author{
D.M.S.P. Bandara, T.M.R. Dissanayake, H.M.A.P. Rathnayake and D.P.C. \\ Swarnasiri
}

\begin{abstract}
Sesame, (Sesamum indicum) is one of the oldest and important oil seed crop in the world. The sesame seed apart from providing edible oil is also rich in protein. A study was carried out to evaluate the performance of a medium scale screw type oil expeller for extracting sesame oil. In fact, the mechanized medium scale method has not been previously applied in the oil expelling industry for sesame seed in Sri Lanka.
\end{abstract}

For this experiment, the popular screw type machine with $25 \mathrm{~mm}$ shaft pitch, $75 \times 315 \mathrm{~mm}$ internal barrel and $4 \mathrm{~kW}$ three phase motor were used. The development was made in order to increase the oil expelling efficiency in terms of extract bar clearance, speed of the main spiral shaft and outer body closer to the exhaust out let. The optimum oil yield was $44 \%$ obtained under $0.2 \mathrm{~mm}$ and $0.3 \mathrm{~mm}$ barrel shaft clearance and the main spiral shaft speed of $75 \mathrm{rpm}$.

The quality of refined oil at maximum oil yield was analysed out in terms of saponification value, free fatty acid and specific gravity. The results obtained for saponification value, free fatty acid and specific gravity were $182.33,3.3 .12 \%$ and $0.917 \mathrm{gcm}^{-3}$.respectively. Color of the sesame oil was closer to the yellow which revealed by the lightness value $\left(L^{*}\right)$ of 26 and positive value $b$ of 8.27 . The capacity and energy consumption per kilograms of refined sesame oil were $39 \mathrm{~kg} / \mathrm{hr}$ and $0.103 \mathrm{kWh} / \mathrm{kg}$. This study reveals that sesame oil could be obtained using the screw type oil expeller and it can be recommended for medium scale entrepreneurs relative to the traditional Sekku method.

Keywords: $\quad$ Sesame oil, Oil extraction, Oil expellers

\section{Introduction}

The sesame is one of the world most important and oldest known oil seed crop (Abou- Gharbia et al., 1997). The sesame crop is adapted and cultivated both in the tropic and temperate zones of the world (Biabani and Pakniyat, 2008). It is grown mostly for the oil extracted from the seed which is edible and use for industrial and pharmaceutical purposes. The oil is used in the production of perfumes, skin conditioning agents, moisturizers, hair creams, bath oil, insecticides, paints, vanishes and drugs (Mohammed and Hamza, 2008).

Sesame Seed (Sesamum indicum) Oil has also been used as medicinal oil for thousands of years. Sesame oil is mentioned in the Vedas as excellent for humans. It is naturally antibacterial for common skin pathogens, such as staphylococcus and streptococcus as well as common skin fungi, such as athlete's foot fungus. It is naturally antiviral. It is a natural anti inflammatory agent.

(http://www.youthingstrategies.com)

Therefore, sesame has been named as a national high priority crop in Sri Lanka. But sesame oil is very expensive and not freely available for consumers whenever, they need. The main constrain for this is unavailability of oil processing machinery and equipments in the market.

The world harvested about 3.84 million metric

$$
\begin{aligned}
& \text { Eng. (Mrs). D.M.S.P. Bandara, B.Sc.Eng. MEng } \\
& \text { (Manufacturing), AMIE (Sri Lanka), } \\
& \text { NSF/STMIS/09/2466, Executive committee member of } \\
& \text { IESL-NCP Centre, Mechanical Engineer, Institute of Post } \\
& \text { Harvest Technology, Anuradhapura. } \\
& \text { Eng. T.M.R. Dissanayake, B.Sc.Eng. MEng, } \\
& \text { AMIE(Sri Lanka) Mechanical Engineer, Institute of Post } \\
& \text { Harvest Technology (IPHT), Anuradhapura, Sri Lanka. } \\
& \text { Eng. H.M.A.P. Rathnayake, B.Sc.Eng., M.Eng, } \\
& \text { AMIE(Sri Lanka) Act. Senior Mechanical Engineer, } \\
& \text { Institute of Post Harvest Technology, Anuradhapura. } \\
& \text { D.P.C. Swarnasiri, B.Sc.(Agric Eng)., MSc(Agr), } \\
& \text { PGDM, Additional Director, Institute of Post Harvest } \\
& \text { Technology, Jayanthi Mawatha, Anuradhapura. }
\end{aligned}
$$


tons of sesame seeds in 2010. The world's largest exporter of sesame seeds was India, andJapan is the largest importer. According to the Export Development Board records Sri Lanka also exports sesame and its annual production as per the records in 2009 of Department of Census and Statistics, Sri Lanka is around $8750 \mathrm{MT}$.

The extraction of sesame oil from the sesame seed is not a completely automated process in Sri Lanka. Even at the present, it is done by using the traditional method called "Sekku" method. However, in some instance, screw type coconut extractors are being used for extraction of sesame oil. But, above methods have not been previously evaluated for their performance. Most of the time, people in different sectors request a perfect medium scale method for sesame oil extraction. Hence, this study aims at evaluating the most common type of extractor available in the market in sesame oil extraction with a view to improving its performance with maximum extraction efficiency.

Expeller pressing (also called oil pressing) is a mechanical method for extracting oil from raw materials. The raw materials are squeezed under high pressure in a single step. When used for the extraction of food oils, typical raw materials are nuts, seeds and algae, which are supplied to the press in a continuous feed. As the raw material is pressed, friction causes it to heat up; in the case of harder nuts (which require higher pressures) the material can exceed temperatures of $120^{\circ} \mathrm{F}$ (Wikipedia). range of $140-210^{\circ} \mathrm{F}\left(60-99^{\circ} \mathrm{C}\right)$ (Wikipedia).

\section{Methodology}

For this experiment, the popular Chinese origin screw type oil expeller machine with $25 \mathrm{~mm}$ pitch of screw shaft, $75 \times 315 \mathrm{~mm}$ internal barrel and 4 $\mathrm{kW}$ three phase motor were used. The machine mainly consists of pressing part, adjustment part and transmission part. This machine, common in coconut oil extraction was used to modify for sesame oil extraction in custom level.

\section{Testing and modifications}

At the first stage, extract bar clearance was adjusted from $0.2 \mathrm{~mm}$ to $0.3 \mathrm{~mm}$.

Generally, the barrel behaves like a simple pressure vessel - the cylindrical shell, computed on the assumption that the stress is uniform throughout the wall thickness. Thus, circumferential or hoop stress oh and longitudinal stress o1 by

$$
\sigma_{h}=\frac{f}{t l}=\frac{\operatorname{PrL}}{t l}=\frac{\operatorname{Pr}}{t}
$$

$\mathrm{f}=$ hoop five $(\mathrm{N}), \mathrm{t}=$ thickness of the cylindrical wall $(\mathrm{m}), 1=$ length of the cylindrical wall $(\mathrm{m}), \mathrm{P}$ $=$ intensity of the internal pressure (N/M2), $\mathrm{r}=$ internal radius of the cylindrical wall $(\mathrm{m})$. The torque $\mathrm{T}$ (in $\mathrm{Nm}$ ) transmitted by wave action and the angular speed (in rad/s) is given by

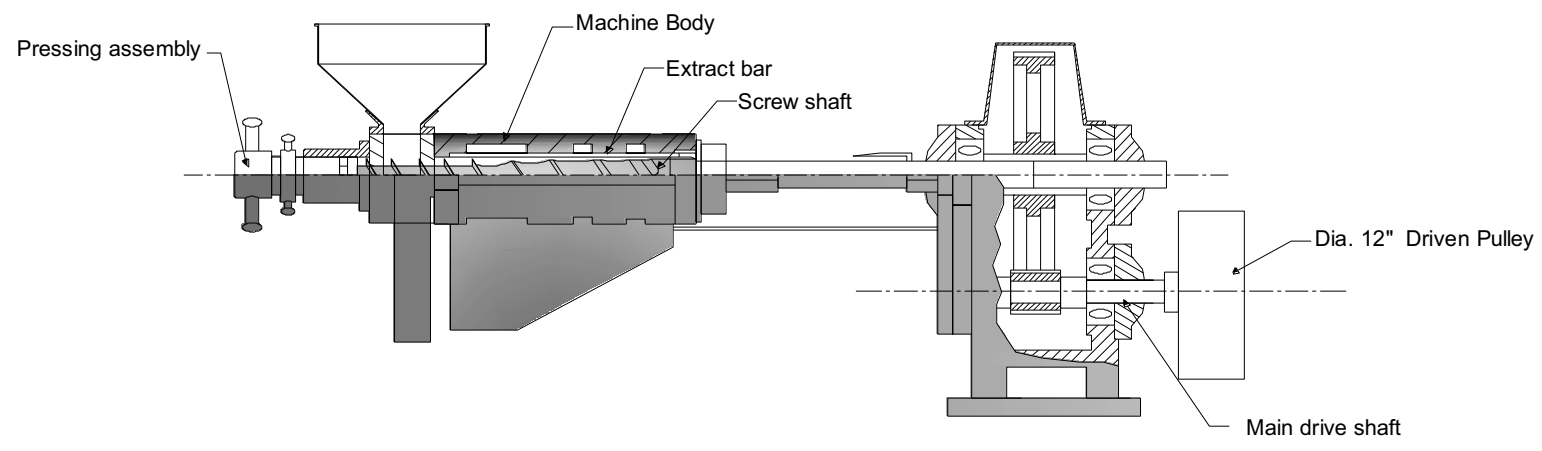

Figure 1 - Sectional view of the screw type oil expeller

An expeller press is a screw-type machine that presses oil seeds through a caged barrel-like cavity. Raw materials enter one side of the press and waste products exit the other side. The machine uses friction and continuous pressure from the screw drives to move and compress the seed material. The oil seeps through small openings that do not allow seed fiber solids to pass through. Afterward, the pressed seeds are formed into a hardened cake, which is removed from the machine. Pressure involved in expeller pressing creates heat in the

$$
\omega=\frac{2 \pi N_{\omega}}{60}
$$

and

$$
\tau=\frac{P}{\omega}=\frac{60 P}{2 \pi N_{\omega}}
$$


$\mathrm{P}=$ power transmitted by wave action $(\mathrm{W})$

$\mathrm{N} \omega=\mathrm{No}$. of $\mathrm{rev} / \mathrm{min}$ of wave action $(\mathrm{rev} / \mathrm{min})$

The screw assembly is formed integrally with this shaft. This screw rotates within a cage or barrel. The barrel is made of case hardened, tool steel bars. The
$\mathrm{T}=$ Time taken for processing $(\mathrm{hr})$

The energy consumption of extraction per kilogram of oil was calculated by considering power consumed by the oil expeller.

Table 1 - Different speed range of main shaft and manual Sekku method

\begin{tabular}{c|c|c|c|c}
\hline $\begin{array}{c}\text { Combination } \\
\text { No: }\end{array}$ & $\begin{array}{c}\text { Diameter of drive } \\
\text { pulley(inch) }\end{array}$ & $\begin{array}{c}\text { Diameter of driven } \\
\text { pulley(inch) }\end{array}$ & Speed ratio & $\begin{array}{c}\text { Speed of screw } \\
\text { shaft RPM }\end{array}$ \\
\hline 1 & 2.5 & 12 & $30: 1$ & 75 \\
\hline 2 & 3 & 12 & $16: 1$ & 90 \\
\hline 3 & 4 & 12 & $12: 1$ & 120 \\
\hline 4 & 6 & 12 & $8: 1$ & 180 \\
\hline 5 & \multicolumn{4}{|c}{ "Sekku" method } \\
\hline
\end{tabular}

clearance spaces are used between the lining bars or rings to allow drainage of the oil as the pressure on the feed material is increased. At the discharge end, a movable choke or cone controls the operating pressure (Ajao, K.R atel, 2009).

The inbuilt belt transmission was consisted with 6 " diameter drive pulley and 12" diameter driven pulley. The rotational speed was set up for four different speeds by varying drive pulley diameter $2.5^{\prime \prime}, 3^{\prime \prime}, 4^{\prime \prime}$ extras and the inbuilt pulley of $6 "$.

As the drive shaft diameter is one inch, the smallest pulley diameter compatible with the drive shaft could only be 2.5 inches. Table: 1 shows how the speed varied using different drive pulleys and their speed ratios. The sample obtained from "Sekku" traditional method was taken for analysis.

A homogeneous bulk sample of sesame seed, belonging to the popular Sri Lankan variety MI-2, was used for the experiment.

Oil yields from the samples were recorded as percentage of raw material fed as stated below.

$$
\begin{aligned}
& \text { Oy= } \frac{o}{S} \text { x100 } \\
& \text { Where, } \\
& \text { Oy } \quad=\text { Oil yield } \\
& O \quad=\text { Crude oil recovered } \\
& S \quad=\text { Mass of the sesame fed }
\end{aligned}
$$

Machine capacity was calculated for each combination.

$$
C=\frac{S}{T} \quad x 100
$$

Where,

$\mathrm{C}=$ Machine capacity $(\mathrm{kg} / \mathrm{hr})$

$\mathrm{S}=$ Mass of the sesame fed $(\mathrm{kg})$
$E=\frac{P}{O} \quad x 100$

Where,

$\mathrm{E}=$ Energy consumption $(\mathrm{kW} / \mathrm{kg})$

$\mathrm{P} \quad=$ Electrical power consumed $(\mathrm{kW})$

$\mathrm{O}=$ Crude oil recovered $(\mathrm{kg})$

Oil weighed and measured the volume then Specific Gravity is calculated using the equations mentioned below.

$$
S G=\frac{W w}{S v} \times 100
$$

Where,

$\mathrm{SG}=$ Specific Gravity $(\mathrm{g} / \mathrm{cm} 3)$

$\mathrm{Ww}=$ Sample weight $(\mathrm{g})$

$\mathrm{Sv}=$ Sample volume $(\mathrm{cm} 3)$

Saponification value indicates the average molecular weight of a fat or oil. According to the AOCS method, Saponification value was calculated.

$$
S P=\frac{(B-S) \times 28.05}{\text { Gram of Sample }}
$$

Where,

$\mathrm{B}-\mathrm{ml}$ of $\mathrm{HCl}$ required by Blank.

$\mathrm{S}-\mathrm{ml}$ of $\mathrm{HCl}$ required by Sample.

Percentage of free fatty acid (ffa) in each sample of sesame oil was calculated according to the AOCS method using equation (6).

$$
\text { FFA }(\%)=V-B^{*} N_{f} * 28.2 / W
$$

Where,

FFA $=$ Free Fatty Acid

$\mathrm{V} \quad=$ Volume of the $\mathrm{NaOH}$ consumed (ml.)

$\mathrm{B}=$ Volume of $\mathrm{NaOH}$ consumed during blank titration (ml.) 
$\mathrm{W} \quad=$ Weight of oil sample $(\mathrm{g})$

$\mathrm{N}=$ Normality of $\mathrm{NaOH}$ factor

The color of the oil samples was determined using a Chroma meter (Konica Minolta, Model CR-400). Representative oil samples were introduced to the Chroma meter and readings of $L^{*} a^{*} b$ values were taken.

Data gathered were analyzed using Analysis of Variance (ANOVA) by Statistical Analysis System (Annon, 2000)

\section{Results and Discussion}

The modification was made including extension of extract bar clearance and overflow outlet. This screw type oil expeller normally uses for coconut oil extraction. The extract bar clearance that was originally $0.1 \mathrm{~mm}$, which was adjusted to 0.2 $\mathrm{mm}$ on one side and $0.3 \mathrm{~mm}$ other side. Another problem was the pressure releasing outlet on the cylindrical body. Before performing the cake, the mixer comming through this whole was mixed with the extracting oil. This was a problem to the quality of extracted oil. For that, the modification was made to direct the pressed mixer to the cake outlet. After the above modification, changing the speed ratios of the machine, the oil expelling trials were conducted as per the speed stated in Table 1 . To evaluate the machinery performance, crude oil speed of $180 \mathrm{rpm}$. And it shows the crude oil yield has been increased when the speed of the screw shaft decreased. The maximum oil yield, of $44 \%$ was obtained at the speed of $75 \mathrm{rpm}$. This speed is the lowest level of speed that only could be achieved by this machine. There is a significant change in between each and every speed level. Beyond this level, pulley diameter of this selected machine couldn't be reduced. To get the speed lower than that, it is needed to change the driven pulley also. There will be a more extra work for users. The highest machinery capacity of $39 \mathrm{~kg} / \mathrm{hr}$ was also achieved at the speed of $75 \mathrm{rpm}$ and it is the most significant change. The lowest energy consumption of $0.103 \mathrm{kWh} / \mathrm{kg}$ in oil extraction is significant at the lowest speed. Considering the percentage of oil yield, Machine Capacity and Energy consumption during expelling, the best performance is given the speed of $75 \mathrm{rpm}$ which could be achieved by the machine without modifying. An oil-rich seed such as sesame seed or groundnut yields about 5 percent less oil in a traditional than in a mechanical expeller. (http:/ /www.fao.org)

The chemical properties of oil are amongst the most important properties that determines the present condition of the oil. Free fatty acid and peroxide values are valuable measures of oil quality (J.M. Nzikou, etal. 2009). In this study, important parameters; Saponification value and

Table 2 - Machinery and quality parameters at different combinations and the Sekku method

\begin{tabular}{|c|c|c|c|c|c|c|c|c|c|}
\hline \multirow[t]{2}{*}{$\begin{array}{c}\text { Combination } \\
\text { No }\end{array}$} & \multirow{2}{*}{$\begin{array}{l}\text { Oil yield } \\
\qquad(\%) \\
\text { (Crude } \\
\text { Oil) }\end{array}$} & \multirow{2}{*}{$\begin{array}{c}\text { Machine } \\
\text { Capacity } \\
(\mathrm{kg} / \mathrm{h})\end{array}$} & \multirow{2}{*}{$\begin{array}{c}\text { Energy } \\
\text { consumption } \\
\text { per } 1 \mathrm{~kg} \\
(\mathrm{kWh} / \mathrm{kg})\end{array}$} & \multirow[t]{2}{*}{$\begin{array}{c}\text { Saponification } \\
\text { Value }\end{array}$} & \multicolumn{3}{|c|}{$\begin{array}{l}\text { Colour Value } \\
\text { (As per HUE) }\end{array}$} & \multirow{2}{*}{$\begin{array}{l}\text { Specific } \\
\text { gravity } \\
\left(\mathrm{gcm}^{-3}\right)\end{array}$} & \multirow{2}{*}{$\begin{array}{c}\text { Free } \\
\text { Fatty } \\
\text { Acid } \\
\text { Content } \\
(\%)\end{array}$} \\
\hline & & & & & $\mathrm{L}^{*}$ & $\mathrm{a}$ & $b$ & & \\
\hline 1 & $44^{\mathrm{a}}$ & $39^{a}$ & $0.103^{c}$ & $182.33^{a}$ & $26.00^{a}$ & -1.48 & 8.27 & $0.917^{a}$ & $3.12^{c}$ \\
\hline 2 & $39 \mathrm{~b}$ & $12^{b}$ & $0.333^{b}$ & $181.48^{b}$ & $24.93^{\mathrm{b}}$ & -2.02 & 11.81 & $0.907 \mathrm{~b}$ & $3.75^{a}$ \\
\hline 3 & $25^{\mathrm{d}}$ & $6^{c}$ & $0.667 a$ & $176.71^{\mathrm{c}}$ & $23.44^{\mathrm{c}}$ & -0.88 & 10.71 & $0.815^{c}$ & $3.69 \mathrm{~b}$ \\
\hline 5 & - & - & - & $182.02^{a}$ & $26.02^{a}$ & -1.64 & 10.28 & $0.910^{\mathrm{a}}$ & $3.20^{c}$ \\
\hline
\end{tabular}

*Any two means in the same column followed by different letters differ significantly according to Duncan's multiple range test $(\mathrm{P}<0.05)$.

yield, machine capacity and energy consumption at different speed of screw shaft were calculated.

Raw sesame contained $\sim 53 \%$ of oil. This confirms previous findings by Al-Adawy and Mansour (2000) who reported a high content of oil for the dehulled sesame seeds (58.9\%). According to the Table 2, there is no oil extraction happened at the the Free fatty acid were measured. Saponification value is significant for every three machine combinations and there is insignificant between the $75 \mathrm{rpm}$ speed of the machine and the Sekku method. The saponification value of samples that were recorded for the machine speed of 75 rpm and Sekku method are 182.33 and 182.02 
respectively. According to the SLSI standards the saponification value for sesame oil is in between 188-193.

Though the Free Fatty Acid value of sesame oil according to the SLSI standards is $2.5 \%$, all the samples in Table 2 exceed the $3.12 \%$. While FFA value is significance among the machine combinations, there is a similar significance value of the $75 \mathrm{rpm}$ speed of the machine and the Sekku method.

According to the Hunter lab $\mathrm{L}^{*}, \mathrm{a}, \mathrm{b}$ colour spaces, positive $a$ is red, Negative a is green, Positive $b$ is yellow, Negative $b$ is blue and $L$ value gives the lightness index of the sample. Table 2 shows all the samples are comply with positive $b$ values that confirmed these all four sample are yellow in colour that is well shown in figure 2 . The $L$ value is significant among the machine combinations and it is insignificant in combination of 1 and 5. It clearly shows that when the machine speed decreases the lightness of the colour increases. There is no significant change in colour between the speed of $75 \mathrm{rpm}$ and Sekku method.

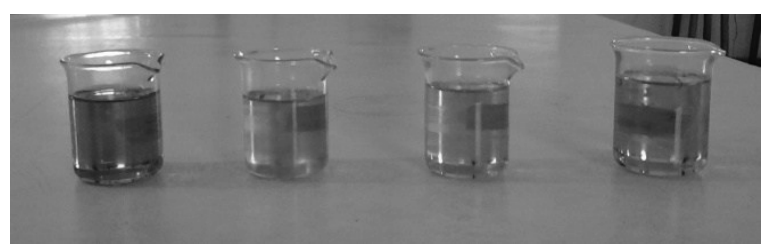

Figure 2 - Oil Colour in treatment 1, 2, 3 and 5 respectively

In overall, Table 2 noticeably shows that all the quality parameters; saponification value, color value, specific gravity and free fatty acid of the 75 rpm sample extracted were not significant with that of the Sekku traditional method. From this research survey, it was found that Sekku traditional method is the most popular method for usage of sesame oil for traditional Ayurvedic treatments.

\section{Conclusion}

The screw type oil expeller which is commonly used in Sri Lanka for extraction of coconut oil in medium and small scale can be economically used for extracting sesame oil. The optimum process parameters for expression of highest yield of crude oil at $44 \%$ and machine capacity of $39 \mathrm{~kg} / \mathrm{hr}$ were obtained under $0.2 \mathrm{~mm}$ and $0.3 \mathrm{~mm}$ barrel shaft clearance and the main spiral shaft speed of $75 \mathrm{rpm}$ at the rate of energy consumption $0.103 \mathrm{kWh} / \mathrm{kg}$.

\section{Acknowledgement}

Sincere thanks are due to Seedevi Importers (Pvt) Ltd, Anuradhapura for financial support for this research project. Authors also like to acknowledge the services of other members of the Institute of Post Harvest Technology (IPHT) for their fullest corporation extended in this regard.

\section{References}

1. Ajao, K. R., Ajimotokan, H. A., and Olaomi, J., "Development and Performance Evaluation of a Groundnut Oil Expelling Machine", New York Science Journal, 2009, 2(6), pp 07-08.

2. Akiniso. R., Igbeka J., and Olajanju T., "Process Optimization of Expression for Sesame Seed (Sesamem indicum Linn)", Agricultural Engineering International: the CIGR Ejournal. Manuscript FP 06011 Vol. VIII December, 2006.

3. Borchani C., Besbes S., Blecker C., and Attia, H., Chemical Characteristics and Oxidative Stability of SesameSeed, Sesame Paste, and Olive Oils, J. Agr. Sci. Tech. (2010) Vol. 12: pp 585-596.

4. Central Bank Report of Sri Lanka 2012.

5. Grown in Congo-Brazzaville, Advance Journal of Food Science and Technology, Chemical Composition on the Seeds and Oil of Sesame (Sesamum indicum) L., pp 6-11, 2009.

6. Mohamed Elleuch, Souhail Besbes, Olivier Roiseux, Christophe Blecker, Hamadi Attia, " Quality characteristics of sesame seeds and by-products", 5030 Gembloux, Belgium, 2006.

7. Pathirana R., Weerasena L. A., Bandara P., "Development and Release of Gamma Rays Induced Sesame Mutant ANK-S2 in Sri Lanka", Tropical Agriculture and Extension pp-19-24, 2000.

8. Sahay, K. M., Singh, K. K., Unit Operations of Agricultural Processing, 2nd ed., Vikas Publishing House, Private Limited, New Delhi, 2005, pp219287.

9. SAS Institute Inc., SAS User's Guide: Statistics. SAS Institute Inc. Cary, NC, 1994.

10. Sesame improvement by induced mutations, Final reports of an FAO/IAEA co-ordinated research project, organized by the Joint FAO/IAEA Division of Nuclear Techniques in Food and Agriculture 1993-1998. 
11. Sri Lanka Standard: 231. Speciation for Sesame, 1973.

http://www.fao.org/docrep/t4660t/t4660t0b. htm\#traditional ghani technology visited on 25.04.2012.

12. http://www.statistics.gov.lk/agriculture/index. htm visited on 21.05.2013.

13. http://www.youthingstrategies.com visited on 21.05.2013.

14. http://en.wikipedia.org/wiki/Expeller_pressing visited on 08.12.2013. 